\title{
Flora da Bahia: Melastomataceae - Tribo Merianieae s.l.
}

\section{Marúcia da Cunha Fagundes ${ }^{1, a} \&$ Andrea Karla Almeida dos Santos ${ }^{2 *}$}

${ }^{1}$ Programa de Pós-Graduação em Botânica, Departamento de Ciências Biológicas, Universidade Estadual de Santa Cruz, Campus Soane Nazaré de Andrade, Ilhéus, Bahia, Brasil.

${ }^{2}$ Instituto Multidisciplinar em Saúde, Universidade Federal da Bahia, Campus Anísio Teixeira, Vitória da Conquista, Bahia, Brasil.

Resumo - É apresentada a flora da tribo Merianieae s.l. (Melastomataceae) para o estado da Bahia. Foram reconhecidos cinco gêneros e 10 espécies. São apresentados chave de identificação, descrições, ilustrações, comentários e mapas de distribuição das espécies na Bahia.

Palavras-chave adicionais: florística, Nordeste, Mata Atlântica, taxonomia.

Abstract (Flora of Bahia: Melastomataceae - Tribe Merianieae s.1.) - The flora of the tribe Merianieae s.l. (Melastomataceae) from Bahia state, Brazil, is presented. Five genera and ten species are recognized. An identification key, descriptions, illustrations, notes, and distribution maps of the species in Bahia are presented.

Additional key words: Atlantic forest, floristics, Northeast Brazil, taxonomy.

\section{MELASTOMATACEAE}

Árvores, arbustos, subarbustos ou ervas, geralmente terrestres, raramente epífitas ou lianas; indumento variado. Folhas simples, geralmente opostas, geralmente decussadas; lâmina plana a revoluta, margens inteiras ou serreadas, (1)3-11(-15) nervuras acródromas, campilódromas, subparalelódromas, hifódromas ou broquidódromas, em geral conectadas por nervuras mais ou menos perpendiculares à nervura mediana; estípulas ausentes. Flores (3)4-6(-10)-meras, geralmente bissexuadas, radiais ou bilaterais, solitárias ou reunidas em inflorescências determinadas, axilares e/ou terminais; hipanto bem desenvolvido, oblongo, campanulado ou urceolado; cálice diali- ou gamossépalo, sépalas em um ou dois ciclos; pétalas livres, prefloração imbricada ou contorta, brancas, róseas, violáceas, roxas, púrpura ou magenta, mais raramente vermelhas, amarelas ou bicolores; androceu geralmente diplostêmone, estames isomorfos, subisomorfos ou dimorfos, geralmente retorcidos na antese, posicionando-se mais para um dos lados da flor, anteras geralmente biloculares ou às vezes uniloculares, deiscência poricida ou às vezes longitudinal, conectivos geralmente espessados, providos de apêndices ou não, raramente com glândula dorsal; ovário sincárpico, com (1)2-6(-10) carpelos, parcial ou totalmente adnatos ao hipanto, súpero a ínfero, com placentação axial ou raramente basal, lóculos uni- a pluriovulados, estilete único, estigma capitado, truncado, punctiforme ou ocasionalmente um pouco lobado; nectários geralmente ausentes. Frutos cápsulas ou bagas; sementes geralmente numerosas,

\footnotetext{
*Autora para correspondência: andreakarlaufba@gmail.com

a maruciacbio@hotmail.com

Editor responsável: Alessandro Rapini

Submetido: 31 maio 2016; aceito: 5 out. 2016

Publicação eletrônica: 17 nov. 2016; versão final: 21 nov. 2016
}

diminutas, de formato variável, sem endosperma (Martins 2009; Souza \& Lorenzi 2012).

A família é extremamente diversa em áreas tropicais, representada por cerca de 5.000 espécies (incluindo Memecylaceae), com aproximadamente dois terços delas limitadas à Região Neotropical (Renner et al. 2016). No Brasil, é a quinta maior família de angiospermas, com 68 gêneros e 1.377 espécies, 899 delas endêmicas, ocorrendo desde a Amazônia e Centro-Oeste até o Rio Grande do Sul, em todos os domínios fitogeográficos e nos mais variados tipos de vegetação (BFG 2015; Flora do Brasil 2020). Para a identificação dos gêneros de Melastomataceae que ocorrem na Bahia, sugerimos a chave de Goldenberg et al. (2012a).

\section{MERIANIEAE s.I.}

Merianieae s.l. é uma tribo neotropical com 16 gêneros e 277 espécies (Renner 1993; MendozaCifuentes \& Fernández-Alonso 2010). No Brasil, está representada por 11 gêneros e 94 espécies, distribuídas nos domínios da Mata Atlântica, Amazônia, Caatinga e Cerrado (Renner 1993; Goldenberg et al. 2016; Flora do Brasil 2020). As espécies que compõem este grupo são representadas por arvoretas, arbustos ou lianas, com folhas (Figura 1) planas e coriáceas, flores geralmente grandes e vistosas, estames (Figura 2) dimorfos ou subisomorfos, com conectivo não prolongado abaixo das tecas ou inconspicuamente prolongado, espessado dorsalmente e em alguns gêneros com apêndices curvos ou bífidos evidentes. Os frutos (Figura 3) são capsulares com sementes achatadas dorsiventral ou lateralmente, obtriangulares, cuneadas, lineares, oblongas, elípticas ou obovais, aladas ou não (Renner 1993; Clausing \& Renner 2001; Baumgratz et al. 2007; MendonzaCifuentes \& Fernandez-Alonso 2010). 

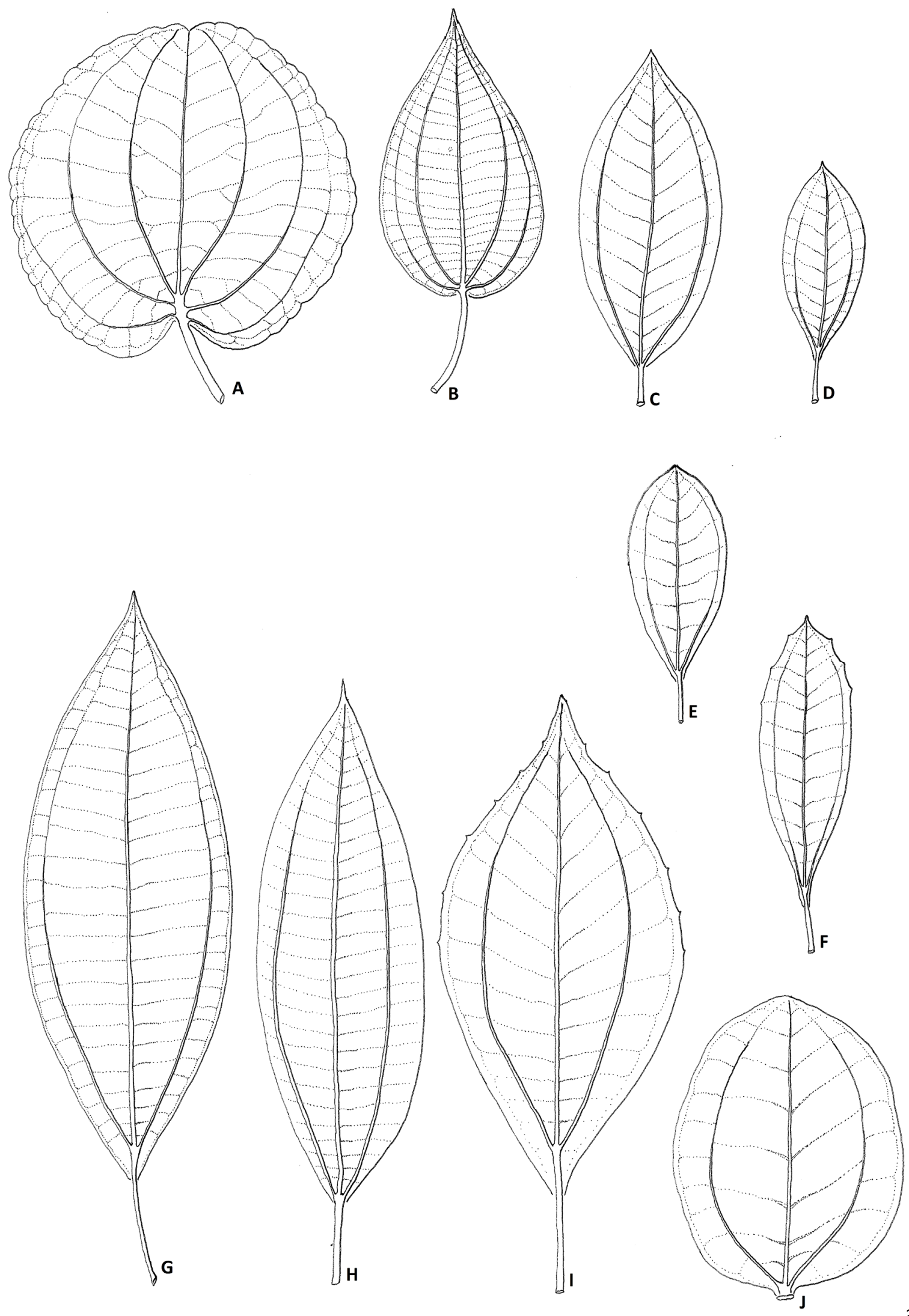

$3 \mathrm{~cm}$

Figura 1. Folhas (face adaxial), evidenciando as nervuras principais das espécies de Merianieae s.l. da Bahia: A- Merianthera pulchra; B- Graffenrieda intermedia; C- Huberia ovalifolia; D, E- H. consimilis; F- Meriania inflata; G- H. carvalhoi; H- Meriania calophylla; I- Meriania tetramera J- H. sessilifolia (A- Mori s.n. CEPEC 10723; B-Amorim 4185 CEPEC; C- Harley 18081 CEPEC; D- Amorim 5484 CEPEC; E- Borges 383 CEPEC; F- Goldenberg 2078 HURB; G- Jardim 5337 CEPEC; H- Alves 98 CEPEC; I- Ferreira 1300 CEPEC 117526; J- Goldenberg 2052 HURB; ilustrado por C.S. Caires). 

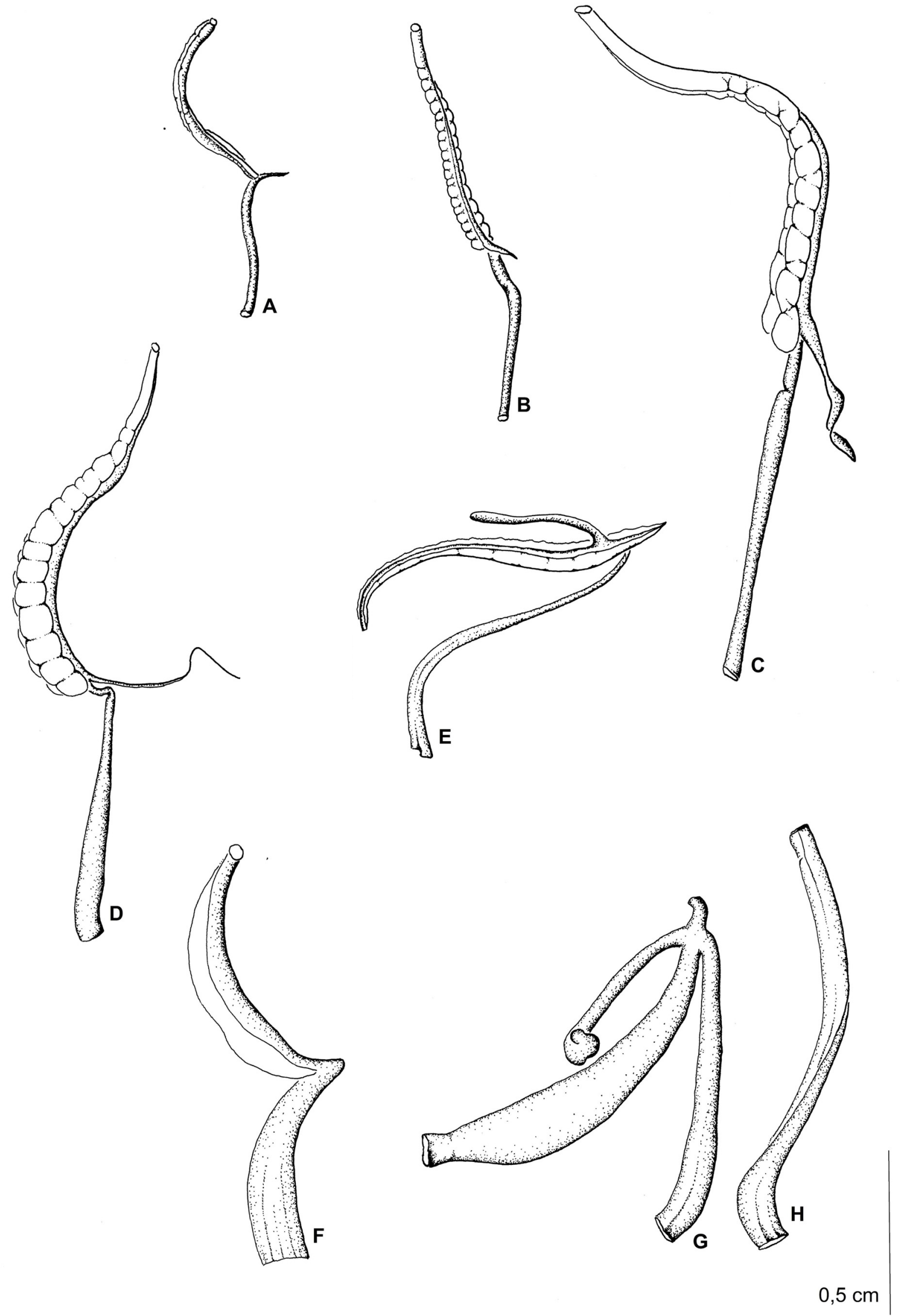

Figura 2. Estames das espécies de Merianieae s.l. da Bahia: A- Graffenrieda intermedia; B- Huberia carvalhoi; C- H. consimilis; D- H. ovalifolia; E- Meriania calophylla; F- Meriania tetramera; G, H- Merianthera pulchra (G- estame antipétalo; H- estame antissépalo) (A- Goldenberg 855 CEPEC; B- Jardim 5337 CEPEC; C- Amorim 5484 CEPEC; D- Harley 18081 CEPEC; E- Eupunino 28 CEPEC; F- Jardim 3929 CEPEC; G, H- Mori s.n. CEPEC 10723; ilustrado por C.S.Caires). 

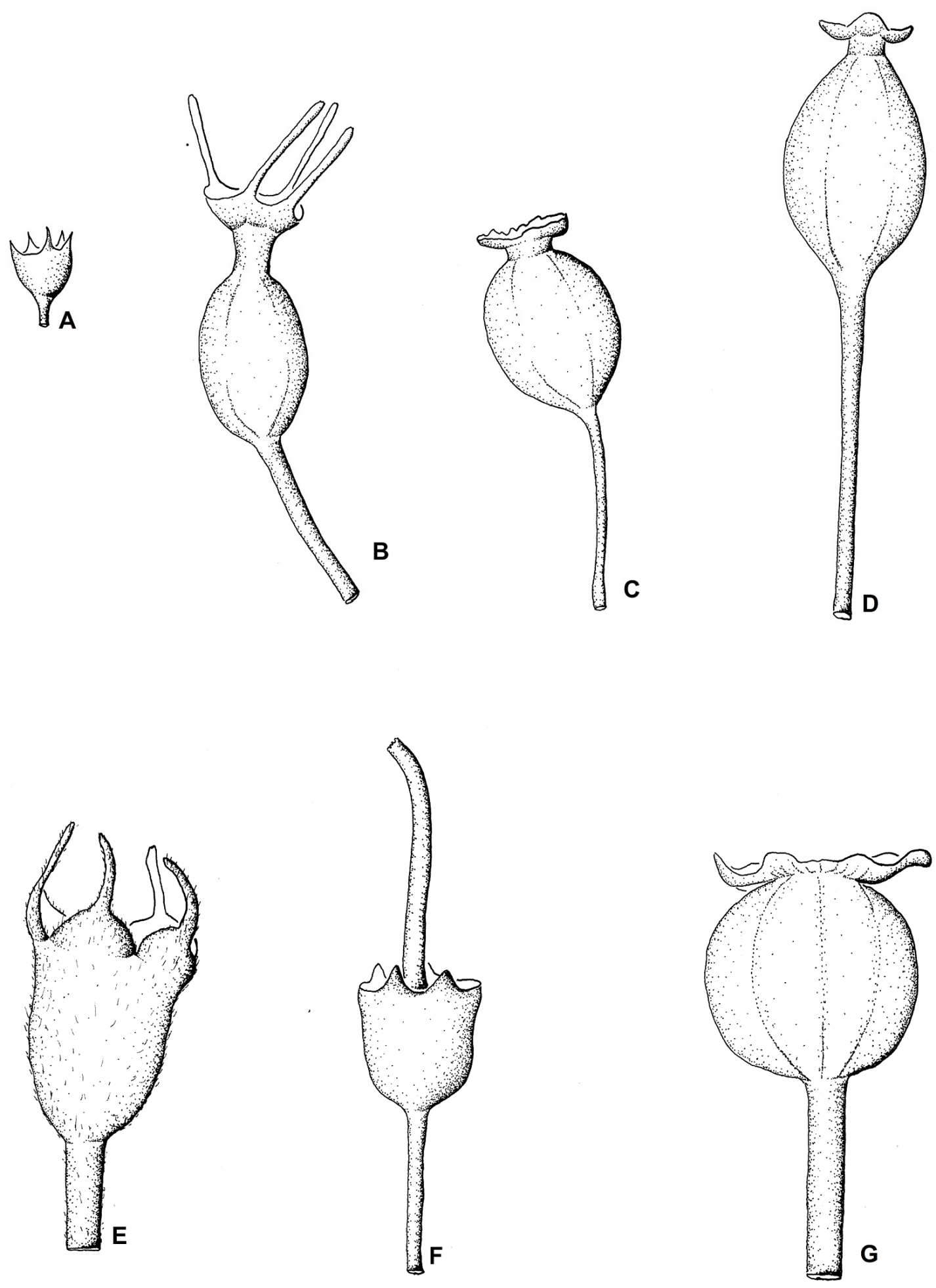

$1 \mathrm{~cm}$

Figura 3. Frutos das espécies de Merianieae s.l. ocorrentes na Bahia: A- Graffenrieda intermedia; B- Huberia carvalhoi; C- H. consimilis; D- H. ovalifolia; E- Meriania calophylla; F- Meriania tetramera (imaturo); G- Merianthera pulchra. (A- Goldenberg 855 CEPEC; B- Jardim 5337 CEPEC; C- Borges 383 CEPEC; D- Mattos-Silva 2658 CEPEC; E- Alves 98 CEPEC; F- Ferreira 1300 CEPEC 117526 ; G- Mori s.n. CEPEC 10723; ilustrado por C.S.Caires).

Conforme demonstrado por Goldenberg et al. (2012a), a tribo, como tradicionalmente circunscrita (Renner 1993), não é monofilética, e seus representantes pertencem a dois clados que não estão proximamente relacionados. Dos cinco gêneros que ocorrem na Bahia, três (Adelobotrys DC., Graffenrieda DC. e Meriania Sw.) pertencem ao clado Merianieae s.str. e dois (Huberia DC. e Merianthera Kuhlm.) estão relacionados ao clado Cambessedesia (Clausing \& Renner 2001; Goldenberg et al. 2012a). Como ainda não há uma classificação formalizada que reflita as relações filogenéticas desses gêneros, estamos adotando aqui a circunscrição tradicional da tribo, que abrange 10 espécies para a Bahia. 


\section{Chave para as espécies}

1. Lianas; ramos com tricomas malpighiáceos 1.1. Adelobotrys atlantica

1'. Arbustos, arvoretas ou árvores; ramos sem tricomas malpighiáceos.

2. Folhas com 7 nervuras principais.

3. Folhas ovais, com margem inteira; sementes aladas

3'. Folhas largo-elípticas, com margem crenada; sementes não aladas

2.1. Graffenrieda intermedia 5.1. Merianthera pulchra

2'. Folhas com 3 ou 5 nervuras principais.

4. Folhas com 3 nervuras principais.

5. Conectivo dos estames com apêndice filiforme longo (3-4 mm compr.) 3.3. Huberia ovalifolia

5'. Conectivo dos estames com apêndice filiforme curto ( $1 \mathrm{~mm}$ compr.) ou achatado.

6. Sépalas aristadas 3.1. Huberia carvalhoi

6'. Sépalas sem arista 3.2. Huberia consimilis

4'. Folhas com 5 nervuras principais.

7. Folhas subsésseis (pecíolo menor que $1,5 \mathrm{~mm}$ compr.); hipanto urceolado .. 3.4. Huberia sessilifolia

7'. Folhas pecioladas (pecíolo 1,5-4(5) cm compr.); hipanto campanulado.

8. Flores 4-meras

4.3. Meriania tetramera

8'. Flores 5-meras.

9. Folhas elípticas a estreitamente elípticas; pétalas verde-pálidas; anteras com sacos inflados na base

4.2. Meriania inflata

9'. Folhas lanceoladas; pétalas lilás a roxas; anteras sem sacos inflados na base

4.1. Meriania calophyla

\section{Adelobotrys DC.}

Lianas ou hemiepífitas, raramente arbustos; indumento com tricomas malpighiáceos. Folhas pecioladas, opostas; lâmina oval-oblonga, membranácea, 3-5 nervuras basais. Inflorescências terminais, tirsoides; brácteas persistentes. Flores 5-meras, pediceladas; hipanto tubuloso, ápice constricto ou alargado, glabro ou piloso; sépalas lobulares, com pequenos dentes externamente; pétalas obovais ou cuneiforme-oblongas; estames 10, isomorfos, anteras linear-subuladas com rostro, conectivos com apêndice ventral ascendente, bífido no ápice; ovário súpero, oblongo, 5-locular, glabro. Frutos cápsulas loculicidas, glabros ou pilosos, polispérmicos; sementes aladas, linear-lanceoladas, triangular-achatadas ou em forma de cunha (Almeda 1981; Schulman \& Hyvönen 2003; Schulman 2008).

Adelobotrys abrange 31 espécies; dessas, 28 ocorrem na América do Sul, principalmente na Amazônia (Schulman 2008). A maioria das espécies é composta por lianas de florestas, um hábito pouco comum em Melastomataceae (Renner 1986). No Brasil, as espécies ocorrem predominantemente na Amazônia, com apenas uma espécie na Mata Atlântica (Flora do Brasil 2020).

\subsection{Adelobotrys atlantica Schulman, Kew Bull. 63(3) 457. 2008 [2009].}

Figura 4.

Lianas; ramos delgados, arredondados a achatados, com tricomas e glândulas, entrenós $6,5-9 \mathrm{~cm}$ compr. Folhas com pecíolo $0,8-1,4 \mathrm{~cm}$ compr.; lâmina estreito-oval, $12,5-14,5 \times 5,1-6,3 \mathrm{~cm}$, face adaxial glabra ou com glândulas esparsas, face abaxial glabra, base cordada, margem serrilhada, plana, ápice acuminado a atenuado. Flores não vistas. Cápsulas com pedicelo 6-7 mm compr., ovoide, hipanto ca. $5 \times$
$4 \mathrm{~mm}$, persistente, constrito no ápice, 10-costado, 5locular; sementes $1-1,5 \times 0,2-0,3 \mathrm{~mm}$, em forma de cunha, superfície lisa, testa alongada em ambas as extremidades (Schulman 2008).

Endêmica da Mata Atlântica do sul da Bahia e conhecida apenas pelo material-tipo, coletado em 1943, perto da cidade de Ilhéus (Schulman 2008). G/H8. Coletada com frutos em março.

Material selecionado - entre Bom Gosto e Olivença, mar. 1943 (fr.), R.L. Fróes 20032 (holótipo NY [foto], isótipo IAN [foto]).

As informações sobre Adelobotrys atlantica estão baseadas na descrição original. Apesar de ocorrer no sul da Bahia, região amplamente coletada nas últimas décadas, essa espécie não foi reencontrada. Pode ser distinta das espécies de Merianieae s.l. da Bahia pelo hábito (liana) e o indumento com tricomas malpighiáceos. É, possivelmente, a única espécie do gênero que ocorre fora da Amazônia. Para Schulman (2008), a falta de coletas dessa espécie está relacionada à antropização da região onde foi coletada, fazendo com que $A$. atlantica esteja criticamente ameaçada (CR) com base nos critérios da IUCN, ou mesmo extinta.

\section{Graffenrieda DC.}

Arbustos ou árvores; indumento com tricomas lepidotos, escamosos ou com glândulas sésseis. Folhas pecioladas; lâmina elíptica, lanceolado-elíptica ou oval, cartácea, 3-9 nervuras basais, raro suprabasais. Inflorescências terminais ou pseudolaterais, paniculadas; brácteas persistentes. Flores 4- ou 5-meras, pequenas (até $10 \mathrm{~mm}$ compr.); hipanto oblongocampanulado, 4- ou 5-angulado, não constrito no ápice, glabro ou frequentemente furfuráceo; sépalas triangulares a deltoides; pétalas obovais a oblongas ou estreito-triangulares; estames 8 ou 10, isomorfos, anteras linear-subuladas, curvadas para fora, conectivos com 
apêndice dorsal descendente; ovário súpero, 2-5 lóculos, glabro ou raramente com cerdas. Frutos velatídeos, polispérmicos; sementes não aladas, oblongas ou linearpiramidais (Mendoza \& Ramírez 2006; Jardim 2010).

Graffenrieda abrange cerca de 44 espécies (Renner 1993); no Brasil, são reconhecidas 17 espécies, concentradas quase que exclusivamente na Amazônia (16 espécies), exceto Graffenrieda weddellii Naudin, que também ocorre no Cerrado e na Mata Atlântica de São Paulo, e G. intermedia Triana, que também ocorre na Mata Atlântica do sul da Bahia.

2.1. Graffenrieda intermedia Triana, Trans. Linn. Soc. London 28(1): 71.1871 [1872].

Figuras 1B, 2A, 3A e 4; Jardim (2010).

Arbustos ou árvores, 1-10 m alt.; entrenós, folhas e inflorescências com tricomas glandularesfurfuráceos, entrenós 2,5-4 cm compr. Folhas com pecíolo 3-6 cm compr.; lâmina oval a oblonga, 6,5$16 \times 3,5-9 \mathrm{~cm}$, cartácea, levemente discolor, face adaxial verde-escura, brilhante, face abaxial verdeopaca, base arredondada a subcordada, margem inteira, plana, ápice agudo a acuminado, 7 nervuras principais. Inflorescências terminais. Flores 4-meras; pedicelo ca. 0,2 cm compr.; hipanto 3-5 × 4-6 mm, não constrito no ápice; sépalas triangulares, ca. $2 \times 3$ $\mathrm{mm}$, base truncada, margem inteira, ápice obtuso; pétalas estreito-triangulares, ca. $5 \times 1 \mathrm{~mm}$, brancas, base truncada, margem inteira, ápice agudo; estames 8, isomorfos, filetes brancos, ca. $2 \mathrm{~mm}$ compr., anteras amarelas, ca. 2,5 $\mathrm{mm}$ compr., conectivos ca. $0,5 \mathrm{~mm}$, porção dorsal ascendente do apêndice ca. 1 mm compr.; ovário (3)4-locular, 2-3 × 1,5-2 mm, tricomas glandulares esparsos, estilete ca. $8 \mathrm{~mm}$ compr. Frutos $2-3 \times$ ca. $2 \mathrm{~mm}$; sementes não aladas, oblongas, ca. $1 \times 0,1 \mathrm{~mm}$.

Além do Brasil, Graffenrieda intermedia é registrada para o Peru, Venezuela e Guiana (Wurdack 1973). F8, G8, H8: Mata Atlântica, em remanescentes de floresta montana no sul da Bahia (Amorim et al. 2009). Coletada com flores nos meses de março, abril e de julho a outubro, e com frutos em janeiro, junho, agosto e setembro, sendo que em todos os meses foram encontrados frutos imaturos, exceto em janeiro, quando foram encontrados apenas frutos secos.

Material selecionado - Almadina, 144'ㄹ'”S, 39³6'12'W, 650-900 m s.n.m., 12 ago. 2007 (fl.), R.O. Perdiz et al. 127 (CEPEC); Arataca, 15²10'25”S, 39²0’30”W, 1000 m s.n.m., 13 abr. 2006 (fl.), R. Goldenberg et al. 855 (CEPEC); Barro Preto, 1446'13”S, 39¹2'10”'W, 600-900 m s.n.m., 3 out. 2006 (fl.), M.M.M. Lopes et al. 1103 (CEPEC); Camacan, 15²2'52"S, 39³4'11”W, 900 m s.n.m., 27 jul. 2005 (fl.), A.M. Amorim et al. 4185 (CEPEC); Wenceslau Guimarães, 20 jan. 2012 (fr.), $M$. Reginato et al. 1301 (CEPEC).

Dentre as espécies da tribo, Graffenrieda intermedia se destaca pelas flores pequenas (até $10 \mathrm{~mm}$ compr., incluindo o hipanto); nas demais espécies, as flores são maiores que $10 \mathrm{~mm}$ compr.

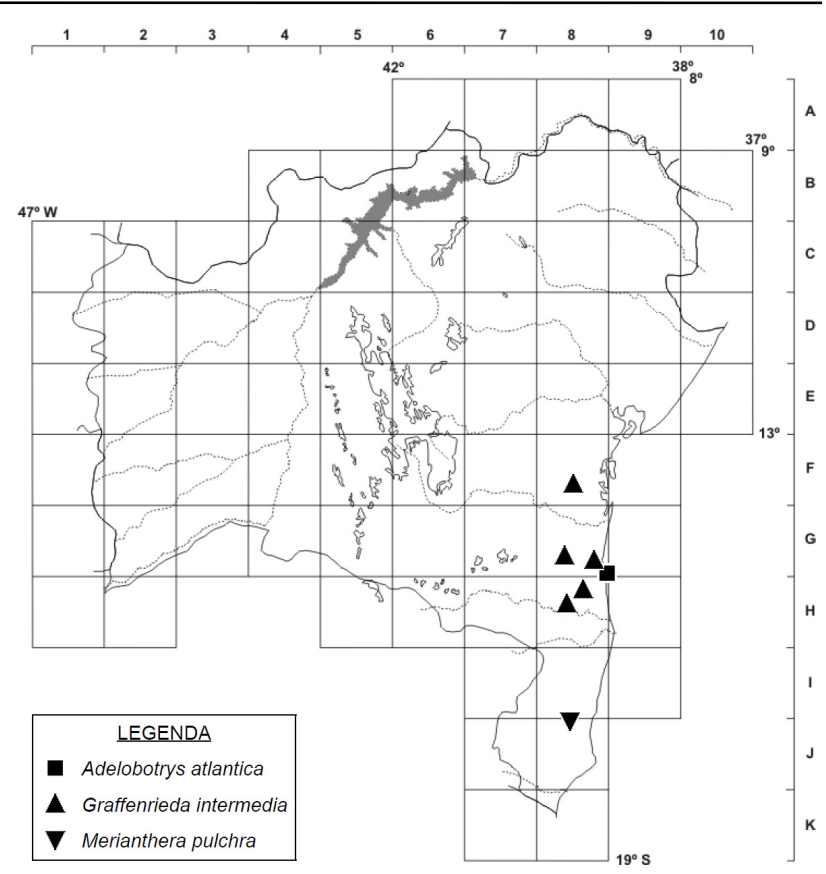

Figura 4. Distribuição de Adelobotrys atlantica, Graffenrieda intermedia e Merianthera pulchra na Bahia.

\section{Huberia DC.}

Arvoretas ou árvores, às vezes arbustos; indumento denso a esparsamente furfuráceo. Folhas pecioladas ou sésseis (em vista superior); lâmina elíptica, oval, oboval ou oblonga, 3(5) nervuras basais ou suprabasais. Inflorescências terminais, às vezes pseudolaterais, cimosas, tirsoides, umbeliformes, corimbosas, botrioides ou tríades, raro mônades; brácteas geralmente caducas. Flores 4(5)-meras, pediceladas; hipanto tubuloso, cilíndrico a oblongourceolado, persistente no fruto, costado ou anguloso, às vezes alado; sépalas triangulares, deltoides, subuladas ou reduzidas a lobos oblongos ou ovais; pétalas ovais a obovais; estames 8(10), subisomorfos ou isomorfos, anteras planas a onduladas, poro ventral, conectivos não prolongados abaixo das tecas, com apêndice dorsal; ovário súpero, (3)4-locular, glabro. Frutos ruptídeos, urceolados, polispérmicos; sementes aladas, planas, côncavas ou naviculares, filiformes, lineares, elípticas, obovais ou ovais, granulado-estriadas (Baumgratz 2004; Goldenberg et al. 2016).

São reconhecidas 17 espécies de Huberia, distribuídas de modo disjunto na costa brasileira e nos Andes, do sul do Equador ao noroeste do Peru (Baumgratz 2004; Goldenberg et al. 2016). No Brasil, são encontradas 13 espécies, ocorrendo na Mata Atlântica, Caatinga e Cerrado (Goldenberg et al. 2016; Flora do Brasil 2020).

\subsection{Huberia carvalhoi Baumgratz, Brittonia 52(1):} 25. 2000.

Figuras 1G, 2B, 3B e 5; Baumgratz (2000).

Nome popular: Mundururu (Mattos-Silva 1767).

Arvoretas ou árvores, 4-10 $\mathrm{m}$ alt.; ramos subtetragonais a tetragonais, entrenós $0,25-0,45 \mathrm{~cm}$ 
compr., glanduloso-furfuráceos. Folhas com pecíolo 1,2-1,7 cm compr.; lâmina elíptica, 7-12,5 × 2,3-5,5 $\mathrm{cm}$, membranácea a cartácea, base cuneada, margem inteira, plana, ápice acuminado, nervuras basais ou suprabasais. Inflorescências terminais, cimosas, corimbosas ou umbeliformes. Flores 4-meras; pedicelo 0,8-1,3 cm compr.; hipanto 7-10 × 2-3 mm compr., urceolado; sépalas triangulares, ca. 5,2 × 2,2 mm, base truncada, ápice aristado, persistentes nos frutos; pétalas obovais, 14-20 × 6,5-8 mm, brancas, base aguda, margem inteira, ápice agudo-assimétrico; estames 8 , isomorfos, filetes avermelhados, 8-9 $\mathrm{mm}$ compr., anteras oblongo-subuladas, onduladas, amarelas, 9-15 mm compr., conectivos espessados, com apêndice dorsal filiforme no ápice ca. $1 \mathrm{~mm}$ compr.; ovário 4locular, ca. $3 \times 1,6 \mathrm{~mm}$, estilete $21-27 \mathrm{~mm}$ compr., estigma truncado. Frutos 8-15 × 6-10 mm; sementes elípticas a estreitamente obovais, às vezes lineares ou estreito-ovais, ca. $5 \times 1,5 \mathrm{~mm}$.

Endêmica do sul da Bahia. F8: florestas de restinga, nas planícies litorâneas. Coletada com flores em janeiro, fevereiro, junho e de agosto a outubro (botões florais) e dezembro, e com frutos em fevereiro, agosto e setembro.

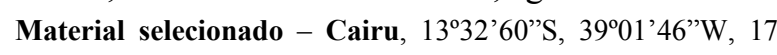
ago. 2008 (fl. fr.), J.G. Jardim et al. 5337 (CEPEC); Nilo Peçanha, 13'33'16”S, 39 $02^{\prime} 07^{\prime \prime}$ 'W, 23 fev. 2000 (fl. fr.), J.G. Jardim et al. 2786 (ALCB, CEPEC); Valença, 10 jan. 1982 (fl.), A.M. Carvalho \& G.P. Lewis 1135 (CEPEC).

Quando comparada com as demais espécies de Huberia da Bahia, H. carvalhoi se destaca pelas sépalas com ápice aristado. Assemelha-se a $H$. ovalifolia, por compartilharem o formato das folhas, tipo de inflorescência, pétalas e estames; porém, $H$. ovalifolia possui conectivos com apêndice dorsal filiforme longo (ca. $4 \mathrm{~mm}$ ) e $H$. carvalhoi, apêndice filiforme curto (ca. $1 \mathrm{~mm}$ ).

\subsection{Huberia consimilis Baumgratz, Brittonia 52(1):} 29. 2000.

Figuras 1D, E, 2C, 3C e 5; Baumgratz (2000).

Arvoretas ou árvores 3-9 $\mathrm{m}$ alt.; ramos subtetragonais a tetragonais, entrenós 1-2 cm compr. Folhas com pecíolo 0,5-1,5 cm compr.; lâmina elíptica a oboval, 5-9 × 2-4,5 cm, subcartácea a cartácea, às vezes membranácea, base cuneada a aguda, margem inteira, às vezes levemente denteada na metade superior, plana, ápice arredondado, agudo ou levemente acuminado, nervuras basais. Inflorescências terminais, cimas corimbosas ou reduzidas, geralmente sésseis ou com pedúnculo reduzido. Flores 4-meras; pedicelo 0,71,2 cm compr.; hipanto 7-8,5 × 2-2,5 mm, tubuloso; sépalas triangulares, ca. $2 \times 1 \mathrm{~mm}$, base truncada, ápice obtuso, geralmente caducas nos frutos; pétalas obovais, 12-17 × 7-12 mm, brancas, base cuneada, margem inteira, ápice agudo, assimétrico; estames 8, subisomorfos, filetes amarelos quando jovem, vináceos quando maduros, 7-9 $\mathrm{mm}$ compr., anteras amarelas, 7,5-9 mm compr., conectivos espessados, apêndice dorsal achatado no ápice 2,5-3 mm compr.; ovário 4- locular, $3-5 \times 1,5-3 \mathrm{~mm}$, estilete ca. $9 \mathrm{~mm}$ compr., estigma punctiforme. Frutos 8-14 × 6-8,5 mm compr.; sementes aladas, lineares a elípticas, 1,5-6 × 2-5 mm.

Endêmica do Brasil, ocorrendo na Bahia, Rio de Janeiro e Pernambuco. E6, E8, F6, F7, F8, G8, H7: florestas de altitude, com distribuição disjunta entre o litoral e a Chapada Diamantina. Coletada com flores e/ou botões florais de dezembro a maio e com frutos de novembro a março.

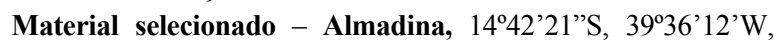
650-900 m s.n.m., 17 dez. 2006 (fl.), R.A.X. Borges et al. 383 (CEPEC); Barra da Estiva, $13^{\circ} 35^{\prime}$ 'S , 41 ${ }^{\circ} 18^{\prime} \mathrm{W}, 1100$ m s.n.m., 29 jan. 1974 (fl.), R.M. Harley 15642 (CEPEC); Elísio Medrado, 1251'S, $39^{\circ} 28^{\prime} \mathrm{W}, 8$ fev. 2011 (fr.), M.L. Guedes et al. 17944 (CEPEC); Ibirapitanga, 1353'27'’S, 39²7'33'W, 690 m s.n.m., 11 dez. 2005 (f1.), A.M. Amorim et al. 5484 (ALCB, CEPEC); Maracás, 900-1000 m s.n.m., 15 fev. 1979 (fr.), T.S. Santos et al. 3458 (CEPEC); Palmeiras, 12²7'00”S, 41²8'00”'W, 1040 m s.n.m., 30 dez. 1994 (fl. fr.), M.L. Guedes et al. 1518 (ALCB, HUEFS); Porto Seguro, 15'15'53'S, 40³4'29'W, 250-536 m s.n.m., 14 nov. 1996 (fr.), W.W. Thomas et al. 11295 (CEPEC); Rio de Contas, 1331'25"S, 41 $57^{\prime} 39^{\prime \prime}$ W, 1665 m s.n.m., 23 fev. 2003 (fl. fr.), R.M. Harley et al. 54953 (HUEFS); Santa Terezinha, $12^{\circ} 45^{\prime}$ 'S, 39³2'W, 800 m s.n.m., 6 jun. 1984 (fl.), L.R. Noblick et al. 3350 (CEPEC).

Dentre as espécies que ocorrem na Bahia, assemelhase a $H$. sessilifolia, pelo apêndice dos conectivos curto, ainda que em $H$. consimilis, ele seja mais longo (2,5-3 $\mathrm{mm}$ vs. 1,3-1,7 mm compr.). Além disso, o pedicelo em $H$. consimilis é geralmente mais longo que em $H$. sessilifolia (7-12 $\mathrm{mm}$ vs. 5,5-7 $\mathrm{mm}$ compr.).

\subsection{Huberia ovalifolia DC., Prodr. 3: 167. 1828.}

Figuras 1C, 2D, 3D e 6.

Nome popular: aderne-mangue (Moraes 3).

Arvoretas ou árvores, 3-8 $\mathrm{m}$ alt.; ramos subtetragonais ou tetragonais, entrenós 1-4 cm compr. Folhas com pecíolo 1,2-2,3 cm compr.; lâmina

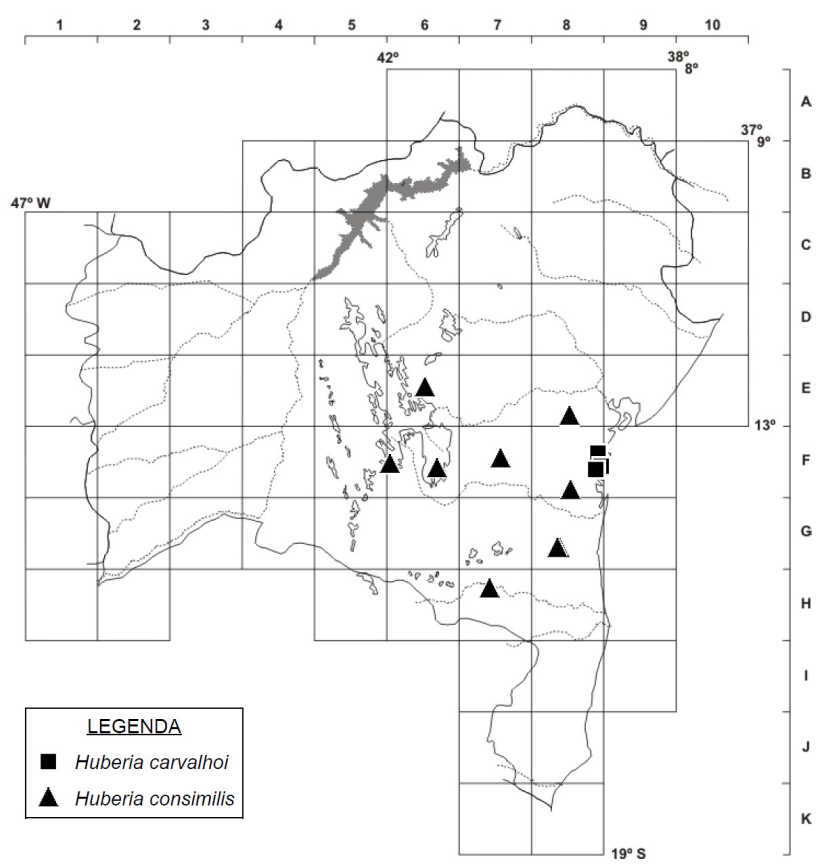

Figura 5. Distribuição de Huberia carvalhoi e H. consimilis na Bahia. 
elíptica, oboval ou oval, 4,2-18,5 × 2,4-3,7 cm, cartácea, coriácea ou membranácea, base obtusa, cuneada, raramente aguda, margem inteira, plana, ápice agudo ou cuspidado, nervuras basais. Inflorescências terminais, cimosas, corimbosas. Flores 4-meras; pedicelo $0,5-1,8 \mathrm{~cm}$ compr.; hipanto 7-13 × 2-4 mm, tubuloso; sépalas ovais, ca. $4 \times 2 \mathrm{~mm}$, base truncada, ápice arredondado, persistente nos frutos; pétalas obovais ou oblongas, 15-24 × 9-13 mm, brancas, base atenuada, margem inteira, ápice arredondado a agudo, assimétrico; estames 8, subisomorfos, filetes amarelos ou vermelhos, 7-8 mm compr., anteras amarelas, 8-9,5 mm compr., conectivos com apêndice dorsal filiforme prolongado 3-4 mm compr., achatado no ápice; ovário 4-locular, ca. $4 \times 1,5 \mathrm{~mm}$, estilete 15-24 mm compr., estigma punctiforme. Frutos 10-15 × 6-9 mm; sementes aladas, lineares, ca. $15 \times 5 \mathrm{~mm}$.

Endêmica do Brasil, com distribuição na Bahia, Espírito Santo, Minas Gerais, Rio de Janeiro e São Paulo. E8, H8, H8/9, I8, J8, J8, K8: matas de tabuleiro em planícies litorâneas ou matas de altitude próximas ao litoral; encontrada com frequência em áreas antropizadas, como margem de rodovias, pastagens e similares. Floresce e frutifica de dezembro a agosto.

Material selecionado - Alcobaça, 20 ago. 1993 (fl. fr.), M.L. Guedes et al. 3543 (ALCB); Camacan/Canavieiras, 12 abr. 1965 (fl.), R.P. Belém \& M. Magalhães 811 (CEPEC); Canavieiras, 22 fev. 1970 (fl.), J.A. Jesus 593 (CEPEC); Caravelas, 19 jun. 1985 (fl., fr.), G.M. Hatschbach \& F.J. Zalma 49503 (CEPEC); Castro Alves, 1251'11'S, 39²8'19”'W, 22 dez. 1992 (fl. fr.), L.P. Queiroz \& T.S.N. Sena 2989 (CEPEC); Cumuruxatiba, $17^{\circ} 13^{\prime} \mathrm{S}, 39^{\circ} 15^{\prime} \mathrm{W}, 0-50 \mathrm{~m}$ s.n.m., 18 jan. 1977 (fl.), R.M. Harley 18081 (CEPEC); Elísio Medrado, 1252'S, 39²8'W, 600 m s.n.m., 13 dez. 1998 (fl.), E.P.F. Moraes \& M.T.S. Stradmann 3 (ALCB, CEPEC); Mucuri, 10 m s.n.m., 20 maio 1980 (fl. fr.), L.A. Mattos-Silva \& T.S. Santos 757 (ALCB, CEPEC); Porto Seguro/Eunápolis, 9 fev. 1972 (fl.), A. Eupunino 213 (CEPEC); Porto Seguro, 100 m s.n.m., 19 jul. 1988 (fl.), G.M. Hatschbach \& J.M. Silva 52252 (CEPEC); Prado/Alcobaça, 10 fev. 1972 (fl. fr.), T.S. Santos 2234 (CEPEC); Prado, 12 ago. 1995 (fl.), G.M. Hatschbach \& J.T Motta 63018 (CEPEC); Santa Cruz Cabrália, 21 fev. 1972 (fl.), A. Eupunino 233 (CEPEC). Teixeira de Freitas, 10 ago. 1972 (fl.), T.S. Santos 2350 (CEPEC).

Huberia ovalifolia é bastante polimórfica; assemelha-se a Huberia carvalhoi (veja o comentário daquela espécie).

\subsection{Huberia sessilifolia R.Goldenb. \& Michelang.,} PeerJ 4: 5. 2016.

Figuras 1J e 6; Goldenberg et al. (2016).

Árvores ou arbustos, 4-5 m alt.; caules jovens levemente quadrangulares ou levemente 4-costados, posteriormente cilíndricos; entrenós 1-4 mm compr. Folhas sésseis, mas a nervura central tem um espessamento na base da folha que pode ser interpretado como um pecíolo reduzido (1-1,5 $\mathrm{mm}$ compr.); lâmina oval a oval-elíptica, em dois tamanhos, as menores em ramos férteis, (2-)3-5 × (1-)1,7-3,7 $\mathrm{cm}$, cartácea, base subcordada a cordada, margem inteira, plana, ápice amplamente agudo a obtuso ou

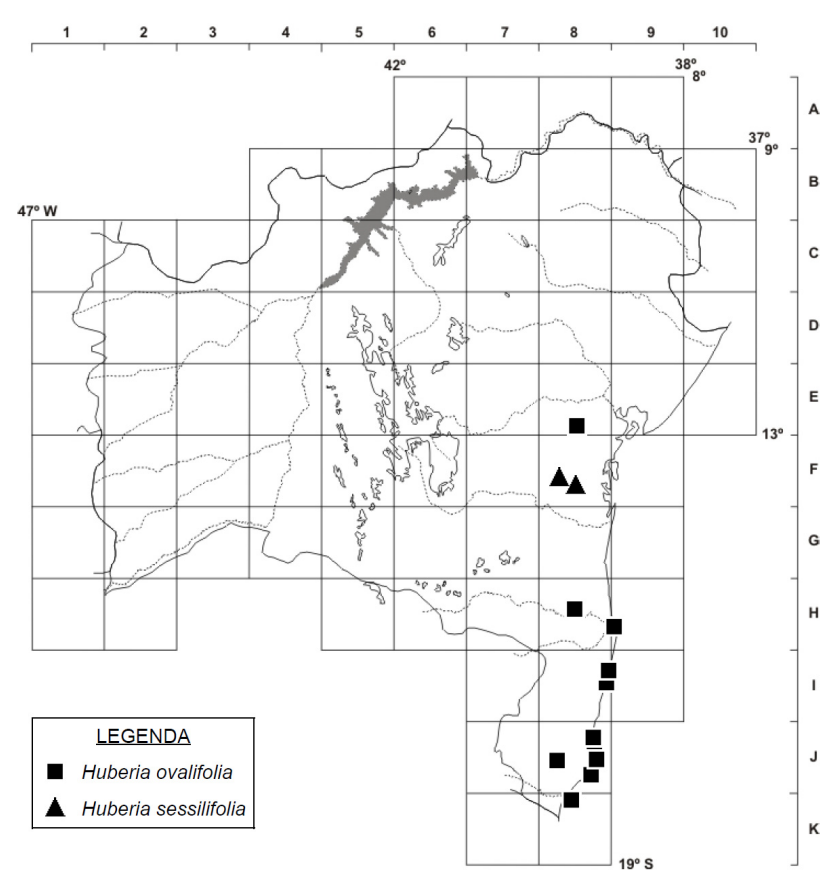

Figura 6. Distribuição de Huberia ovalifolia e $H$. sessilifolia na Bahia.

arredondado, as maiores em ramos estéreis, ca. $9 \times 5$ $\mathrm{cm}$, margem denticulada, plana, ápice agudo a obtuso, 5 nervuras principais. Inflorescências geralmente terminais, cimas umbeliformes. Flores 4-meras; pedicelo 5,5-7 $\mathrm{mm}$ compr.; hipanto 5,5-6,5 × 2-2,5 mm compr., cilíndrico a oblongo-urceolado; sépalas largamente deltoides, 1-1,3 mm compr., apêndice dorsal 0,5-0,7 mm compr.; pétalas obovais, assimétricas, 11$13 \times 8-9,5 \mathrm{~mm}$, brancas, ápice arredondado, com pequena projeção assimétrica; estames 8, isomorfos, filetes amarelos, 6-7,5 $\mathrm{mm}$ compr., anteras amarelas a vermelho-alaranjadas, 7,7-8,5 mm compr., conectivos com apêndice reto, subulado, 1,3-1,7 mm compr.; ovário 4-locular, 4-4,5 mm compr., estilete 13-14,5 mm compr., estigma punctiforme. Frutos jovens 10-12 mm compr.; sementes não vistas (Goldenberg et al. 2016).

Endêmica do sul da Bahia, conhecida apenas da Estação Ecológica Estadual de Wenceslau Guimarães. F8: floresta submontana, em área rochosa de altitude. Coletada com flores em outubro e com frutos imaturos em fevereiro (Goldenberg et al. 2016).

Material examinado - Wenceslau Guimarães, 133' 17.1'S, 3943'04.3”W, 750 m s.n.m., 12 out. 2014 (fl), R. Goldenberg \& F.A. Michelangeli 2052 (holótipo UPCB [foto], isótipo HURB).

De acordo com Goldenberg et al. (2016), Huberia sessilifolia difere das demais espécies do gênero principalmente pelas folhas sésseis com base cordada ou subcordada. Dentre as espécies que ocorrem na Bahia, assemelha-se a $H$. consimilis (ver comentários naquela espécie).

\section{Meriania Sw.}

Arvoretas ou árvores; indumento glandulosopontuado, esparso-pubérulo, furfuráceo-dendrítico e/ou 
tomentoso. Folhas pecioladas; lâmina oblongolanceolada, 3 ou 5 nervuras basais ou suprabasais, com ou sem domácias. Inflorescências terminais e/ou pseudolaterais, cimosas ou paniculadas; brácteas geralmente cedo caducas. Flores 4- ou 5-meras, pediceladas; hipanto campanulado, crasso, zona do disco glabra; sépalas inconspícuo-bilobadas; pétalas oblongas a obovais; estames 8 ou 10, dimorfos ou subisomorfos, anteras curvas a falciformes, uniporadas, conectivos prolongados com apêndice dorsal; ovário semi-ínfero, 4- ou 5-locular. Frutos velatídeos, 10costados; sementes achatadas lateralmente, obtriangulares, curto-rostradas ou não, testa lisa ou áspera a granulada (Chiavegatto \& Baumgratz 2008).

Meriania é um gênero neotropical com cerca de 50 espécies, distribuídas do México ao sul do Brasil, geralmente em áreas de mata. No Brasil, está representado por 14 espécies, a maioria restrita à Mata Atlântica do Sudeste, principalmente no Rio de Janeiro, onde ocorrem 10 espécies. Na Mata Atlântica da Bahia, assim como na Amazônia, ocorrem apenas três espécies (Chiavegatto \& Baumgratz 2011; Goldenberg et al. 2016; Flora do Brasil 2020).

De acordo com Chiavegatto \& Baumgratz (2008), as espécies de Meriania formam um grupo coerente e todas têm como característica marcante o apêndice do conectivo estaminal com a porção ascendente paralela à antera.

4.1. Meriania calophylla (Cham.) Triana, Trans. Linn. Soc. London 28(1): 67. 1871 [1872].

Figuras 1H, 2E, 3E e 7; Cogniaux (1886-1888: tab. 8).

Árvores 8-10 m alt.; ramos quadrangulares, entrenós ca. 1,5 cm compr. Folhas com pecíolo 1,82,7 cm compr.; lâmina lanceolada, 10-15,5 × 3-4,5 $\mathrm{cm}$, coriácea, discolor, face adaxial glabra, face abaxial com tricomas hirtos ferrugíneos, base arredondada, margem inteira, levemente revoluta, ápice levemente acuminado, 3 nervuras suprabasais ou 5 nervuras (3 medianas suprabasais e 2 laterais basais, submarginais), sem domácia. Inflorescências terminais, paniculadas. Flores 5-meras; pedicelos 2-3 cm compr.; hipanto ca. $20 \times 7 \mathrm{~mm}$, não constrito no ápice, com tricomas furfuráceos; sépalas estreitotriangulares, lobadas, ca. $4 \times 1 \mathrm{~mm}$, base truncada, ápice arredondado; pétalas obovais, 13-27 × 6-15 mm, lilás a roxas, base atenuada, margem inteira, ápice truncado, assimétrico; estames 10, subisomorfos, filetes vináceos, achatados, ca. $12 \mathrm{~mm}$ compr., anteras amarelas, com par de sacos inflados na base, 6-9 mm compr., conectivos com apêndice dorsal ca. $4 \mathrm{~mm}$ compr.; ovário 5-locular, ca. $10 \times 3 \mathrm{~mm}$; estilete curvo no ápice, ca. $15 \mathrm{~mm}$ compr. Frutos 9-11 × 5-6,5 mm; sementes piramidais, oblongas, ca. 1,5 ×0,3 mm.

Endêmica do Brasil, com distribuição na Mata Atlântica do sul da Bahia e do Espírito Santo (Flora do Brasil 2020). H8, I8: Mata Atlântica, em floresta ombrófila. Coletada com flores em novembro e dezembro e com frutos em dezembro.
Material selecionado - Porto Seguro, 20 dez. 2005 (fl., fr.), L.J. Alves 98 (ALCB, CEPEC); Porto Seguro/Eunápolis, 25 nov. 1971 (fl.), A. Eupunino 28 (CEPEC).

Meriania calophylla é semelhante a $M$. tetramera pelo formato das folhas e do fruto. No entanto, $M$. calophylla apresenta flores 5-meras (vs. 4-meras), pétalas lilás a roxas (vs. brancas), lâminas foliares lanceoladas (vs. oblongo-lanceoladas) e frutos com tricomas furfuráceos (vs. glabros).

\subsection{Meriania inflata Michelang. \& R.Goldenb., PeerJ} 4: 9.2016.

Figuras 1F e 7; Goldenberg et al. (2016).

Árvores maiores que $16 \mathrm{~m}$ alt.; ramos jovens quadrangulares, posteriormente cilíndricos, entrenós ca. $2 \mathrm{~cm}$ compr. Folhas com pecíolo 1,5- 4(5) $\mathrm{cm}$ compr.; lâmina elíptica a estreitamente elíptica, 11,5$21 \times 4-8,5 \mathrm{~cm}$, cartácea, face adaxial aparentemente glabra, mas com esparsos tricomas simples adpressos, face abaxial escurecida pela pilosidade, com tricomas levemente maiores que na face adaxial, base aguda a estreitamente aguda, margem inteira, levemente revoluta, ápice agudo a levemente acuminado, 5 nervuras (3 medianas suprabasais e 2 laterais basais, submarginais), sem domácias. Inflorescências terminais, cimas reduzidas. Flores 5-meras; pedicelo 8$11 \mathrm{~mm}$ compr.; hipanto 4,5-5,5 × 5,5-6,8 mm, largamente campanulado, com tricomas furfuráceos; sépalas largamente deltoides, 2,5-3,2 mm compr., com apêndice dorsal tuberculado até $1,8 \mathrm{~mm}$ compr., base truncada, ápice arredondado; pétalas obovais, 9-12,5 × 6,7-8 mm, verde-pálida, base truncada, margem inteira com tricomas, ápice emarginado; estames 10, levemente dimorfos, filetes brancos, 7,5-8,5 mm compr.; anteras brancas, translúcidas, cada antera com um saco inflado na base, 2,3-3,3 mm compr., conectivos amarelopálidos, com um apêndice dorsal preto, não

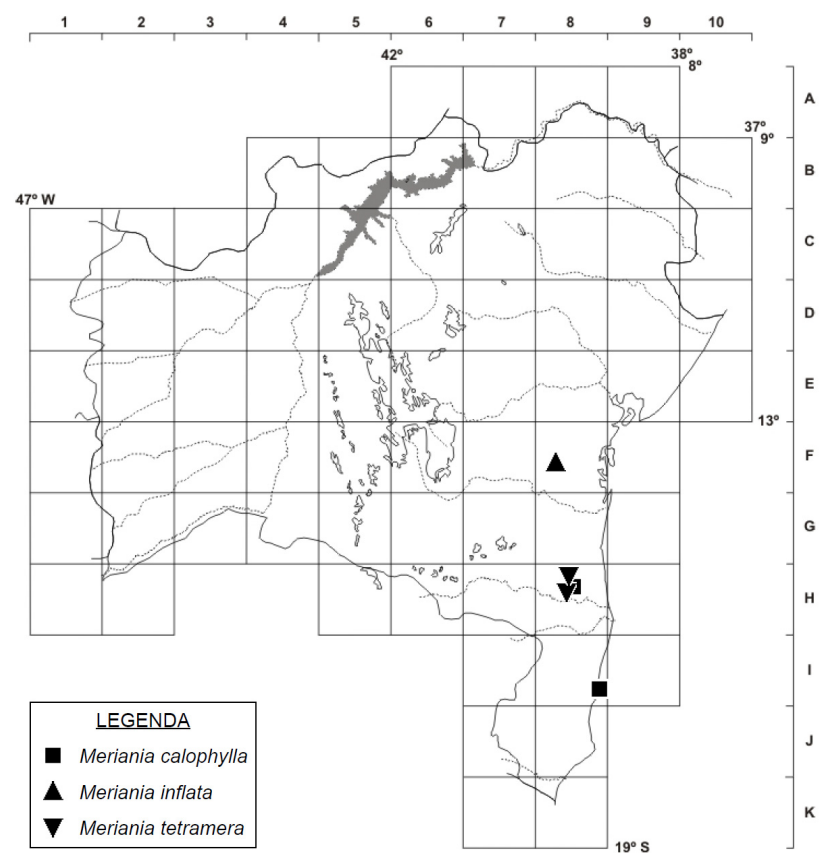

Figura 7. Distribuição das espécies de Meriania na Bahia. 
prolongados abaixo das anteras; ovário 5-locular, 11$13,5 \times 0,9-1 \mathrm{~mm}$, estilete 11-13,5 mm compr. Frutos e sementes não vistos (Goldenberg et al. 2016).

Endêmica do sul da Bahia. F8: floresta submontana. Coletada com flores em outubro.

Material examinado - Wenceslau Guimarães, 1334'28.3"S, 39²'58.8”'W, 675 m s.n.m., 13 out. 2014 (fl), R. Goldenberg \& F. A. Michelangeli 2078 (holótipo UPCB [foto], isótipo HURB).

Meriania inflata se assemelha a $M$. tetramera pelo par de sacos inflados na base das anteras, mas difere por apresentar flores pentâmeras. Também se assemelha a M. calophylla pelo indumento das folhas e do hipanto; no entanto, $M$. calophylla tem folhas geralmente mais estreitas (3-4,5 vs. 4-8,5 cm larg.) e pétalas maiores (13-27 × 6-15 vs 9-12,5 ×6,7-8 mm), de cor púrpura a lavanda (vs. verdes-pálida) (Goldenberg et al. 2016).

\subsection{Meriania tetramera Wurdack, Phytologia 45(4):} 324. 1980. Goldenberg (2012).

Árvores 5-15 m alt.; ramos achatados, entrenós 1,9-2,9 cm compr. Folhas com pecíolo 2,5-4 cm compr.; lâmina oblongo-lanceolada a lanceolada, 11$20 \times 3,5-6 \mathrm{~cm}$, membranácea, concolor, face adaxial glabra, verde-brilhante, face abaxial com tricomas esparsos a glabra, verde-opaca, base aguda, margem levemente serreada ou inteira, plana, ápice atenuado, 5 nervuras (3 medianas suprabasais e 2 laterais basais, submarginais). Inflorescências terminais, cimas corimbosas ou reduzidas. Flores 4-meras; pedicelo 1,5-2 cm compr.; hipanto 6-10 × 6-8 mm, não constrito no ápice, glabro; sépalas internas largamente triangulares, ca. $1,5 \times 0,5 \mathrm{~mm}$, as externas triangulares, ca. $1 \times 0,4 \mathrm{~mm}$ compr., base truncada, ápice arredondado; pétalas obovais, 14-19 × 7-8 mm, brancas, base aguda, margem inteira, ápice arredondado; estames 8, subisomorfos, filetes brancos, 6-7 mm compr., anteras brancas, com um par de sacos inflados na base, 4,9-8,1 $\mathrm{mm}$ compr., conectivos roxos, prolongados abaixo das anteras; ovário 5locular, ca. $4 \times 4 \mathrm{~mm}$; estilete 12,5-17 $\mathrm{mm}$ compr. Frutos 7-15 × 4-6,2 mm; sementes numerosas, piramidais a piramidal-oblongas, ca. 1,5 ×0,5 mm.

Endêmica do Brasil, com distribuição na Mata Atlântica do sul da Bahia e do Espírito Santo (Flora do Brasil 2020). H8: floresta montana. Coletada com flores em agosto e setembro e com frutos em setembro.

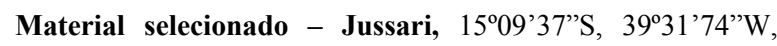
450-600 m s.n.m., 15 set. 2001 (fl., fr.), J.G. Jardim 3929 (CEPEC); Camacan, 15²3'30”S, 39³3'55”'W, 835-1000 m s.n.m., 26 ago. 2007 (fl.), F.M. Ferreira et al. 1300 (CEPEC 117526).

Assemelha-se a $M$. calophylla e $M$. inflata (veja os comentários daquelas espécies).
Figuras 1I, 2F, 3F e 7; Meirelles (2011) e Meirelles \&

caducas; lâmina largo-elíptica a elíptica, 4-8 nervuras principais. Inflorescências terminais ou laterais, paniculadas ou flores isoladas. Flores 5(6)-meras, pediceladas; hipanto campanulado; brácteas caducas. Sépalas regular ou irregularmente lobadas. Pétalas obovais a elípticas. Estames 10(12), dimorfos, anteras ligeiramente arqueadas dorsalmente, um conectivo basal (descendente) e um apical ereto (ascendente), porções ascendentes sempre com dois lóbulos. Ovário ínfero, 4ou 5-locular. Frutos ruptídeos. Sementes numerosas, piramidais, testa rugosa (Martins 2009; Goldenberg et al. 2012b).

Merianthera é endêmico de afloramentos rochosos do leste do Brasil, com sete espécies, distribuídas pela Bahia, Espírito Santo e Minas Gerais. Pode ser reconhecido pelas folhas caducas, incomum entre as Melastomataceae de Mata Atlântica, com lâmina mais larga que longa, e os estames com apêndices dorsais complexos, também característicos do gênero (Goldenberg et al. 2012b; Goldenberg \& Michelangeli 2016).

5.1. Merianthera pulchra Kuhlm., Arq. Inst. Biol. Veg. 1(3): 231. 1935.

Figuras 1A, 2G, H, 3G e 4; Goldenberg et al. (2012).

Árvores ca. $8 \mathrm{~m}$ alt.; entrenós $3-4 \mathrm{~cm}$ compr. Folhas com pecíolo 2,2-2,5 cm compr.; lâmina largoelíptica, ca. $10 \times 10,3 \mathrm{~cm}$, base cordada, margem crenada, plana, ápice arredondado, 7 nervuras. Inflorescências terminais, paniculadas. Flores 5-meras; pedicelo ca. $1 \mathrm{~cm}$ compr.; hipanto 7-8 $\times$ 3-4 mm, constrito no ápice; sépalas regular ou irregularmente lobadas, ca. $6 \times 1 \mathrm{~mm}$, base truncada, ápice agudo; pétalas obovais, 20-22 × 13-14 mm, lilás, base atenuada, margem inteira, ápice arredondado, assimétrico; estames 10, glabros, filetes lilás, achatados, 10-13 mm compr., anteras roxas e lilás, dorsalmente arqueadas, $7-8 \mathrm{~mm}$ compr., conectivos com lobos curvados para trás nos estames antissépalos e não curvados nos antipétalos; ovário 5-locular, ca. $4 \times 2 \mathrm{~mm}$, soldado até a metade do hipanto, estilete curvado, ca. $15 \mathrm{~mm}$ compr., estigma globoso. Frutos 9,5-12 × 10-12 mm; sementes piramidais, testa rugosa, 1,5-2 × 0,5-1 mm.

Endêmica do Brasil, ocorrendo na Bahia, Espírito Santo e Minas Gerais, sendo ainda pouco representada nos herbários da Bahia. I/J8: floresta de altitude. Coletada com flores e frutos em setembro.

Material selecionado - Itamaraju, 19 set. 1978 (fl., fr.), S. Mori et al. s.n. (CEPEC 10723).

Merianthera pulchra se destaca no gênero por possuir os estames antissépalos com filetes mais longos e anteras mais curtas e os antipétalos com filetes mais curtos e anteras mais longas.

\section{Agradecimentos}

5. Merianthera Kuhlm.

Arbustos ou arvoretas; indumento pouco a moderadamente glândulo-granuloso. Folhas pecioladas,
Agradecemos aos curadores dos herbários ALCB, CEPEC, HUEFS e HURB, pela disponibilização dos 
materiais analisados; ao Programa PIBIC/UFBA e ao CNPq/PROTAX (processo 158757/2013-0), pelas bolsas de Iniciação Científica à primeira autora; à Fundação de Amparo à Pesquisa do Estado da Bahia FAPESB / PPP T.O. 0038/2011, pelo apoio financeiro; ao Dr. Claudenir Simões Caires, pela leitura e revisão inicial do manuscrito, e confecção das pranchas, bem como aos revisores anônimos pelas correções e sugestões finais.

\section{REFERÊNCIAS}

Almeda J.R.F. 1981. The Mexican and Central American species of Adelobotrys (Melastomataceae). Annals of the Missouri Botanical Garden 68: 204-212.

Amorim, A.M.; Jardim, J.G.; Lopes, M.M.M.; Fiaschi, P.; Borges, R.A.X.; Perdiz, R.O. \& Thomas, W.W. 2009. Angiospermas em remanescentes de floresta montana no sul da Bahia, Brasil. Biota Neotropica 9: 313-348.

Baumgratz, J.F.A. 2000. Two new species of Huberia (Melastomataceae: Merianieae) from Brazil. Brittonia 52(1): 24-33.

Baumgratz, J.F.A. 2004. Sinopse de Huberia DC. (Melastomataceae: Merianieae). Revista Brasileira de Botânica 27: 545-561.

Baumgratz, J.F.A.; Souza, M.L.D.E.R. \& Tavares, R.A.M. 2007. Melastomataceae na Reserva Ecológica de Macaé de Cima, Nova Friburgo, Rio de Janeiro, Brasil I-Tribos Bertolonieae, Merianieae e Microlicieae. Rodriguésia 58: 797-822.

BFG [The Brazil Flora Group] 2015. Growing knowledge: an overview of Seed Plant diversity in Brazil. Rodriguésia 66(4): $1085-1113$.

Chiavegatto, B. \& Baumgratz, J.F.A. 2008. Meriania (Melastomataceae; Merianieae) no Rio de Janeiro, Brasil. Rodriguésia 59: 899-913.

Chiavegatto, B. \& Baumgratz, J.F.A. 2011. Typification and synonymy of Meriania species (Merianieae-Melastomataceae) from Brazil. Kew Bulletin 66: 167-169.

Clausing, G. \& Renner, S.S. 2001. Molecular phylogenetics of Melastomataceae and Memecylaceae: implications for character evolution. American Journal of Botany 88: 486-498.

Cogniaux, A. 1886-1888. Melastomataceae. In: C.F.P. Martius, A.G. Eichler \& I. Urban (eds), Flora Brasiliensis. Vol. 14, pars 4. Frid. Fleischer, Lipsiae, p. 63-558.

Flora do Brasil 2020 em construção. Jardim Botânico do Rio de Janeiro. Disponível em <http://floradobrasil.jbrj.gov.br/>; acesso em nov. 2016.

Goldenberg, R.; Baumgratz, J.F. \& D'el Rei Souza, M.L. 2012a. Taxonomia de Melastomataceae no Brasil: retrospectiva, perspectivas e chave de identificação para gêneros. Rodriguésia 63(1): 145-161.
Goldenberg, R.; Fraga, C.N.; Fontana, A.P. \& Nicolas, A.N. 2012b. Taxonomy and phylogeny of Merianthera (Melastomataceae). Taxon 61: 1040-1056.

Goldenberg, R.; Michelangeli, F.A.; Aona, L.Y. \& Amorim, A.M. 2016. Angiosperms and the Linnean shortfall: three new species from three lineages of Melastomataceae at one spot at the Atlantic Forest. PeerJ 4: e1824.

Jardim, A.Q.B.S. 2010. Melastomataceae de Floresta Montana na RPPN Serra das Lontras, Bahia, Brasil. Dissertação de Mestrado. Universidade Estadual de Feira de Santana.

Martins, A.B. 2009. Melastomataceae. In: M.G.L. Wanderley, G.J. Shepherd, T.S. Melhem, A.M. Giulietti \& S.E. Martins (eds), Flora Fanerogâmica do Estado de São Paulo. Vol. 6. Fapesp, São Paulo, p. 1-167.

Meirelles, J. 2011. A Família Melastomataceae no Parque Estadual do Forno Grande, Espirito Santo. Dissertação de Mestrado. Universidade Federal do Paraná.

Meirelles, J. \& Goldenberg, R. 2012. Melastomataceae do Parque Estadual do Forno Grande, Espírito Santo, Brazil. Rodriguésia 63(4): 831-855.

Mendoza-Cifuentes, H. \& Fernandez-Alonso, J.L. 2010. Evaluación de caracteres del cáliz y de los estambres en la tribu Merianieae (Melastomataceae) y definición de homologías. Revista de la Academia Colombiana de Ciencias 34: $143-172$.

Renner, S.S. 1986. The neotropical epiphytic Melastomataceae: phytogeographic patterns, fruit types, and floral biology. Selbyana 9: 104-111.

Renner, S.S. 1993. Phylogeny and classification of the Melastomataceae and Memecylaceae. Nordic Journal of Botany 13: 519-540.

Renner, S.S.; Triebel, D.; Almeda, F.; Stone, D.; Ulloa, C.U.; Michelangeli, F.A.; Goldenberg, R. \& Mendonza-Cifuentes, H. Melastomataceae.Net. 2016. A site with information on the biodiversity of Melastomataceae. Disponível em www.melastomataceae.net; acesso em outubro 2016.

Schulman, L. 2008. Adelobotrys atlantica (Melastomataceae: Merianieae): the first species of Adelobotrys from Brazil's Mata Atlântica. Kew Bulletin 63: 457-461.

Schulman, L. \& Hyvönen, J. 2003. A cladistic analysis of Adelobotrys (Melastomataceae) based on morphology, with notes on generic limits within the tribe Merianieae. Systematic Botany 28(4): 738-756.

Souza, V.C. \& Lorenzi, H. 2012. Botânica Sistemática: guia ilustrado para identificação das famílias de fanerógamas nativas e exóticas no Brasil, baseado em APG III. 3 ed. Instituto Plantarum, Nova Odessa.

Wurdack, J.J. 1973. Melastomataceae. In: T. Lasser (ed.), Flora de Venezuela. Vol. 8. Edición Especial del Instituto Botánico, Caracas, p. 1-819.

\section{LISTA DE EXSICATAS}

Alves, L.J. 98 (4.1); Amorim, A.M. 4185 (2.1), 5484 (3.2), 6099 (2.1); Belem, R.P. 811 (3.3); Borges, R.A.X. 383 (3.2); Carvalho, A.M. 1135 (3.1); Eupunino, A. 28 (4.1), 176, 213, 233 (3.3); Ferreira, F.M. 1300 (CEPEC 117526) (4.3), 1300 (CEPEC 117717) (2.1); Froes, R.L. 20032 (1.1); Goldenberg, R. 855 (2.1), 2052 (3.4), 2078 (4.2); Guedes, M.L. 1518 (3.2), 3543 (3.3), 17944 (3.2); Harley, R.M. 15642 (3.2), 18081 (3.3), 54953 (3.2); Hatschbach, G.M. 49503, 52252, 63018 (3.3); Jardim, A.B. 6, 9, 16 (2.1); Jardim, J.G. 2786 (3.1), 3929 (4.3), 4285 (3.2), 5337 (3.1); Jesus, J.A. 593 (3.3); Loizeau, P.A. 555 (3.1); Lopes, M.M.M. 732 (3.2), 1065, 1103 (2.1); Magalhães, C.M. 
145 (3.3); Mattos-Silva, L.A. 757 (3.3), 1767, 2578 (3.1), 2658 (3.3); Milliken, W. 5104 (2.1); Moraes, E.P.F. 3 (3.3); Mori, S. s.n. CEPEC 10723 (5.1); Noblick, L.R. 3350 (3.2); Paixão, J.L. 855 (3.2); Perdiz, R.o. 127 (2.1); Pinheiro R.S. 1075 (3.2), 2136 (3.3); Queiroz, L.P. 2989 (3.3); Reginato, M. 1301 (2.1); Santos, T.S. 2234, 2350 (3.3), 2660 (3.1), 3458 (3.2); Thomas W.W. 11295 (3.2). 